\title{
Bot Chat : Customer Relation dengan Teknologi Artificial Intelligence
}

Putu Kussa Laksana Utama ${ }^{a}$

Fakultas Dharma Duta, IHDN Denpasar

\begin{abstract}
The application of Artificial Intelligence (Al) is increasingly massive in the industries. One of the advantages of implementing $A$ l is operational efficiency, because by using Al that is implemented on computer machines, the use of human as an operator in an industry can be minimized. This certainly affects the operational efficiency of an organization. One form of Al implementation in the industries is the Chatbot program. Chatbot is a virtual program that is able to communicate like a human. In many cases, Chatbot take role in the FrontEnd section of an organization that functions as a customer relations medium. This paper aims to examine various techniques of developing Chatbot for the past 8 years in the academic research environment. In this paper there are 6 scientific articles reviewed focusing on the their techniques and methods of development. The results obtained show that there has been a shift or development of Chatbot's communication features, from the original symbol-based computer keyboard to audiobased speech recognition. Also, there are variations in the construction of knowledge bases, ranging from AIML to semantic based.
\end{abstract}

Keywords Artificial Intelligencel, Bot Chat, Customer Relation

a kussa_laksana@ihdn.ac.id 


\section{PENDAHULUAN}

Articial Intelligence (Al) atau biasa juga disebut sebagai Kecerdasan Buatan adalah konsep di bidang IImu Komputer untuk menjelaskan setiap perangkat yang mampu tanggap terhadap lingkungan di sekitarnya dan mengambil tindakan untuk memaksimalkan hasil yang ingin dicapai (Russel dan Norvig, 2003). Implementasi Al di dunia industri telah dilakukan secara masif.

Beberapa keunggulan yang dapat diperoleh dari implementasi Al di dunia industri adalah proses automatisasi pekerjaan. Di era industri klasik, pekerjaan dilakukan oleh manusia, namun di era industri berbasis teknologi informasi pekerjaan-pekerjaan tersebut diambil alih oleh mesin komputer. Menurut analisis dari McKinsey, sedikitnya 5\% pekerjaan bisa diselesaikan secara otomatis, artinya bisa diambil alih oleh mesin. Fungsi Al secara spesifik dalam automatisasi industri ini adalah membantu mesin komputer agar dapat tanggap dan berperilaku seperti manusia. relasi antara manusia dan mesin. Pada gambar tersebut dijelaskan bahwa Al berfungsi sebagai mediator yang menterjemahkan input-input yang diberikan oleh manusia. Input-input tersebut kemudian dimodelkan sehingga menjadi unit masukan yang dapat dimengerti oleh mesin. Mesin kemudian memberi respon yang bisa dimengerti oleh manusia. Oleh karena peran Al sangat penting dalam konsep ini.

Beberapa industri yang telah menggunakan Al dalam proses bisnis mereka adalah industri Keuangan dan Perbankan. Contoh produk berbasi Al dalam industri keuangan dan perbankan adalah layanan transaksi online. Manajemen investasi dan perdagangan juga merupakan salah satu produk berbasis Al yang dimiliki industri keuangan dan perbankan. Industri kesehatan juga merupakan salah satu industri yang intensif menerapkan Al dalam produk-produk mereka. Babylon Al doctor merupakan salah satu produk

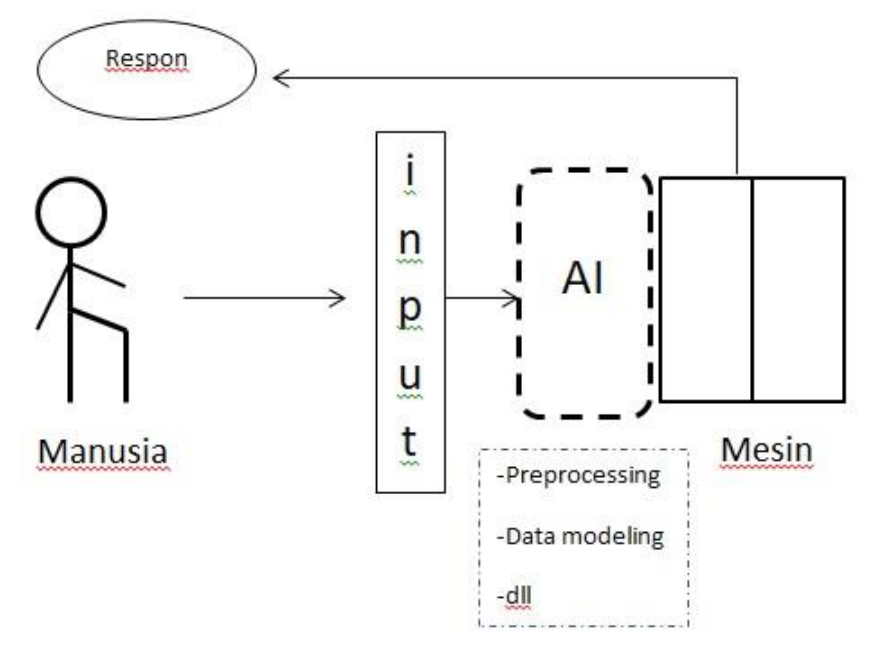

Gambar 1. Peran Al dalam hubungan manusia dan mesin

Gambar 1 berikut menunjukan contoh bagaimana Al berperan dalam teknologi di dunia kesehatan yang telah memanfaatkan Al. Aplikasi ini mampu 
mampu berkomunikasi dengan pasien, memeriksa gejala-gejala pasien dan kemudian mampu menawarkan perawatan yang dibutuhkan. Semua proses interaksi dilakukan secara otomatis. Produk lain yang serupa dengan Babylon Al Doctor adalah Smart Doctor yang dikembangkan oleh Khan dan Bhatti (2017). Gambar 2 berikut merupakan tampilan antar muka teknologi Smart Doctor. penelitian terkini tentang Bot Chat sebagai produk implementasi Al.

\section{PEMBAHASAN}

Definisi Bot Chat

Bot Chat atau yang sering disebut juga sebagai Chat Robot, Chatter Bot, atau Bot adalah suatu program komputer yang didesain untuk melakukan percakapan virtual dengan manusia (Mauldin, 1994). Percakapan virtual yang dimaksud disini adalah komunikasi

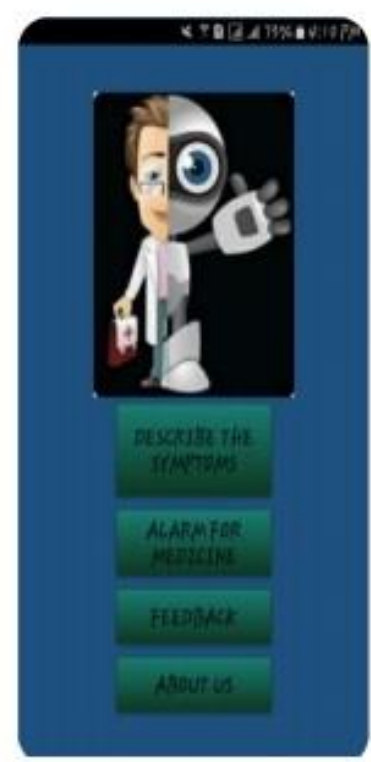

Gambar 2. UI Smart Doctor (Sumber: Khan \& Batti, 2017)

Bentuk lain dari implementasi Al dalam industri adalah penggunaan Bot Chat sebagai media customer relation. Beberapa contoh Bot Chat yang telah dikenal secara luas di dunia industri adalah Nduranc, Casper, Disney, MedWhat. Dalam pembahasan artikel ini akan dijelaskan konsep dasar mengenai Bot Chat dalam perannya sebagai media Customer Relation dan yang dilakukan di dunia digital dan komunikan yang saling berkomunikasi bisa jadi bukan manusia. Bot Chat disebut sebagai bentuk paling modern dari interaksi antara manusia dan komputer. Interaksi klasik manusia dan komputer yang hanya berupa interaksi input melalui simbol-simbol tombol keyboard dan mouse telah beralih menuju interaksi dialog layaknya manusia melalui Bot Chat. 
Gambar 3 berikut menjelaskan bagaimana Bot Chat bekerja dalam konteks Customer Relationship. Pada beberapa tahun terakhir. Penggunaan fitur speech recognition atau pengenalan suara manusia sudah

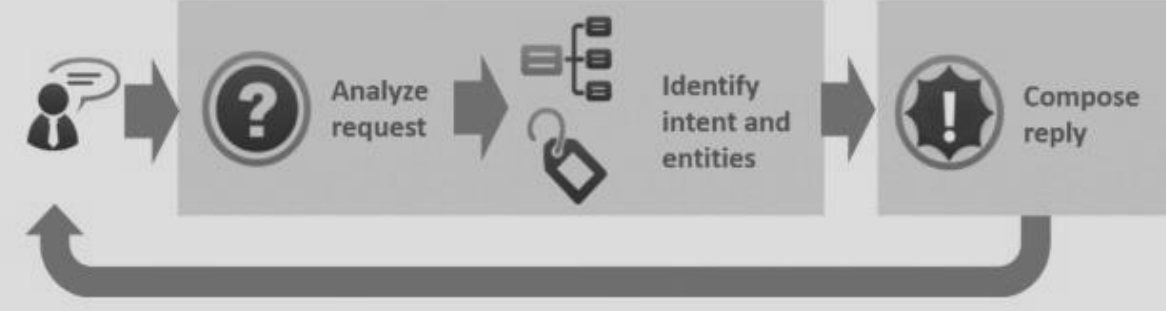

Gambar 3. Contoh alur proses Bot Chat dalam domain Customer Relationship (Sumber: https://expertsystem.com/Bot Chat)

gambar tersebut dijelaskan bagaimana proses yang terjadi dalam system Bot Chat. Apabila diperhatikan dengan seksama maka alur proses Bot Chat mirip dengan konsep interaksi manusia dan komputer dengan Al.

Bot Chat memiliki peran penting dalam proses bisnis suatu organisasi. Bot Chat dapat memangkas waktu yang dibutuhkan dalam berinteraksi antara manusia (customer) dengan sistem. Selain dapat memangkas waktu interaksi, dari segi biaya penggunaan, Bot Chat menawarkan efisiensi bagi organisasi penyedia jasa karena mengurangi pengeluaran untuk membayar pekerja di bagian Customer Service. Abbasi dan Kazi (2014) dalam tulisannya yang berjudul "Measuring Effectiveness of Learning Bot Chat Systems on Student's Learning Outcome and Memory Retention" menyatakan bahwa pembelajaran melalui Bot Chat memiliki dampak yang signifikan dalam hal meningkatkan retensi memori dan hasil belajar bagi siswa (Abbasi dan Kazi, 2014).

\section{Teknik desain Bot Chat}

Teknik desain Bot Chat mengalami perkembangan yang signifikan dalam diterapkan secara masif dan menjadi preferensi bagi pengembang Bot Chat di seluruh dunia. Fitur speech recognition diterima secara luas sebagai bentuk masa depan antara manusia dan komputer. Penggunaan speech recognition meninggalkan pola interaksi klasik yang bergantung pada keyboard, mouse, dan touchscreen (Abdul-Kader dan Woods, 2015). Penggunaan fitur speech recognition sangat membantu user Bot Chat yang memiliki keterbatasan fisik sehingga tidak dapat menggunaan anggota tubuh (tangan, jari) untuk berinteraksi dengan komputer.

Input yang digunakan sebagai unit masukan dalam program Bot Chat adalah teks dalam bentuk natural language. Meskipun suatu program Bot Chat telah dilengkapi dengan fitur speech recognition, namun fitur audio tersebut akan dikonversi menjadi teks terlebih dahulu sebelum diproses lebih jauh. Menariknya, output atau respon yang diberikan oleh komputer kepada manusia bisa berupa teks atau audio. Artinya, ada proses dekonversi kembali dari teks menjadi audio. 
Menurut Abdul-Kader dan Woods (2015), minimal ada 3 bagian yang harus dipahami dalam mendesain program Bot Chat yaitu: Responder, Classifier, dan Graphmaster. Responder adalah bagian yang bertugas untuk menangani proses transfer data dari user dan menangani kontrol input dan output. Sedangkan Classifier adalah bagian yang berfungsi untuk melakukan filterisasi, normalisasi, segmentasi input dan kemudian mentransfernya menuju Graphmaster. Kemudian Graphmaster adalah bagian yang berfungsi untuk melakukan pattern matching yang mengorganisasikan basis pengetahuan yang dimiliki oleh program dan kemudian memetakannya berdasarkan input dari user. Gambar $4 a$ berikut menunjukan 3 bagian yang dimaksud. Sedangkan gambar $4 \mathrm{~b}$ menjelaskan apabila fitur input dari user adalah audio. dan tiap-tiap bagian terdiri dari 9 pertanyaan. Fungsi dari Bot Chat ini adalah sebagai media komunikasi/dialog virtual bagi pasien penderita diabetes.

Peneliti yang sama, Lokman dan Zain (2010) dalam artikel lainnya yang berjudul "One-Match and All-Match Categories for Keywords Matching in Bot Chat" mengembangkan program Bot Chat mereka dengan menambahkan teknik pattern matching untuk meningkatkan akurasi proses retrieval Bot Chat tersebut. Adapun program Bot Chat yang digunakan sebagai basis eksperimen adalah ViDi. Prinsip dasar dari teknik pattern matching yang dikembangkan adalah dengan mengekstraksi keyword yang terasosisasi dengan kalimat sampel.

Bhargava dan Maheswari (2009) dalam artikelnya yang berjudul "An Intelligent Speech Recognition System for Education System" mengusulkan

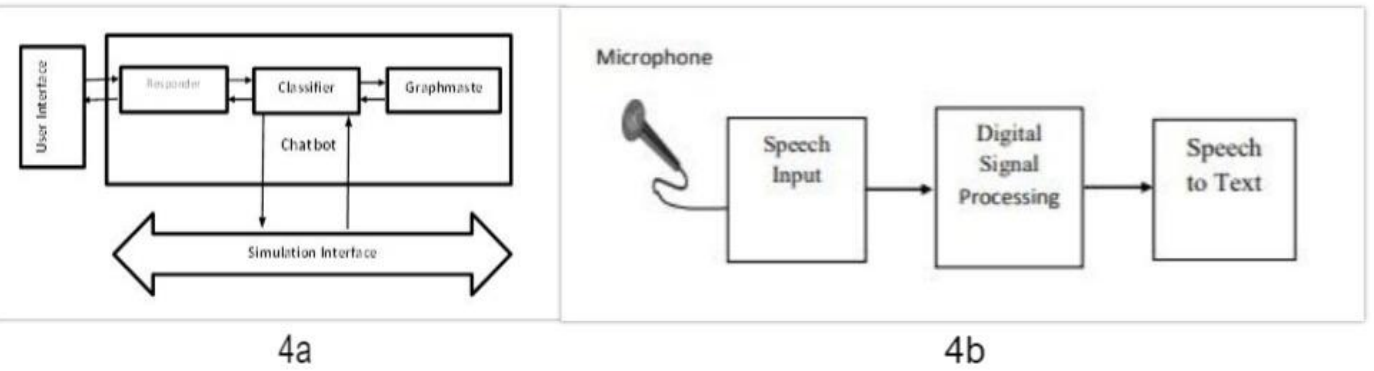

Gambar 4. Tiga bagian dari program Bot Chat: a) alur secara umum; b) alur untuk fitur speech recognition (Sumber: Abdul-Kader \& Woods, 2015)

\section{Perkembangan teknik desain Bot Chat} Lokman dan Zain (2009) dalam artikel yang berjudul "An architectural design of VirtualDietitian (ViDi) for diabetic patients" memperkenalkan teknik untuk mengingat conversational paths selama proses dialog terjadi antara manusia dan program Bot Chat. Seluruh path terbagi menjadi 3 bagian suatu system pembelajaran untuk orang-orang dengan kategori Difabel (tuna netra dan kelumpuhan tangan). Penggunaan fitur yang diusulkan adalah speech recognition dimana user cukup berbicara dengan bahasa manusia kepada program Bot Chat, dan Bot Chat akan merespon user. Sistem telah dirancang menggunakan pengetahuan AIML dasar dengan kosakata terbatas 
termasuk voice recognition atau kelompok fonem dan kata-kata. System yang dikembangkan diklaim memiliki akurasi sebesar $75 \%$, dalam artian $75 \%$ bahasa manusia dapat dikenali dan direspon oleh program Bot Chat. Gambar 5 berikut menunjukan blok diagram system pembelajaran yang dikembangkan oleh Bhargava dan Maheswari (2009). diterapkan pada berbagai domain aplikasi.

Amilon (2015) dalam artikelnya yang berjudul "Bot Chat with commonsense database" mengembangkan program Bot Chat dengan menggunakan pendekatan berbasis common-sense database ConceptNet. ConceptNet merupakan jaringan semantik yang digunakan untuk memahami bahasa

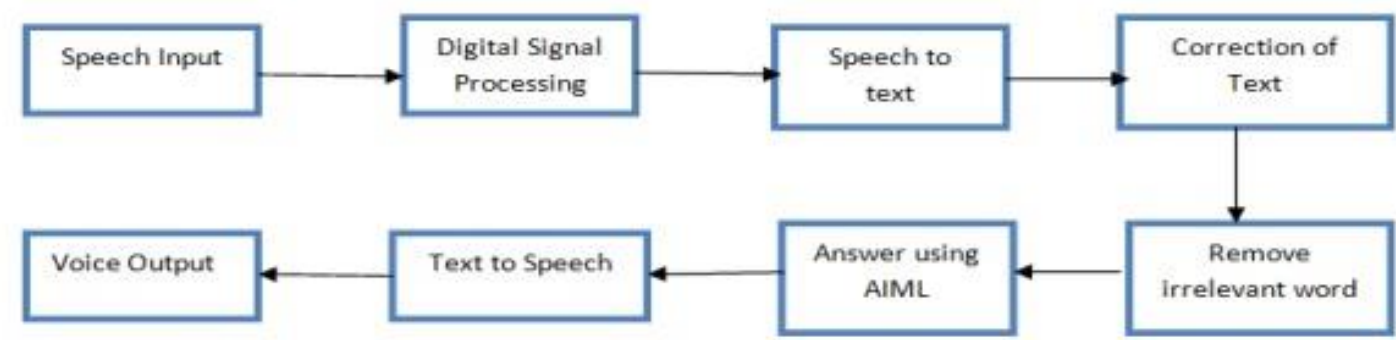

Gambar 5. Blok diagram system pembelajaran Bot Chat (Sumber: Bhargava \& Maheswari, 2009)

Al-Zubaide dan Issa (2011) dalam artikelnya yang berjudul "OntBot: Ontology based Bot Chat" mengusulkan suatu pendekatan berbasis Ontologi dalam membangun basis pengetahuan untuk program Bot Chat yang dikembangkannya. Berbeda dengan penelitian yang dilakukan oleh Bhargava dan Maheswari (2009) yang masih bersandar pada teknologi AIML untuk membangun basis pengetahuan, ALZubaide dan Issa memetakan pengetahuan dan ontologi ke dalam basis data relational. Dengan menggunakan pendekatan seperti ini, para pengembang atau peneliti program Bot Chat tidak lagi perlu mempelajari bahasa pemrograman khusus untuk Bot Chat seperti AIML. Selain itu tingkat interferensi botmaster juga mencapai angka yang tinggi. Keunggulan lainnya adalah pendekatan seperti ini dapat atau kata-kata yang digunakan manusia. Dalam penelitiannya Amilon membangun program Bot Chat sederhana dengan menggunakan ConceptNet dan kemudian membandingkan performanya dengan beberapa program Bot Chat yang sudah terkenal seperti Bot Chat klasik ELIZA dan Bot Chat pemenang penghargaan Loebner pada 2008 yaitu Elbot. Hasil perbandingan dengan berbagai program Bot Chat tersebut dapat dilihat pada Tabel 1.

Tabel 1. Perbandingan hasil pengujian dengan Bot Chat lain (Sumber: Amilon, 2015)

\begin{tabular}{|c|c|c|c|}
\hline $\begin{array}{l}\text { Category \Bot } \\
\text { Chat }\end{array}$ & $\begin{array}{l}\text { This } \\
\text { project }\end{array}$ & ELIZA & Elbot \\
\hline $\begin{array}{ll}\text { Turing } & \text { test } \\
\text { (human-like) } & \end{array}$ & 21 & 17 & 28 \\
\hline Ease of usage & 64 & 46 & 65 \\
\hline Clarity & 25 & 28 & 22 \\
\hline Naturalness & 24 & 26 & 38 \\
\hline Friendliness & 45 & 49 & 42 \\
\hline
\end{tabular}




\begin{tabular}{lccc}
\hline $\begin{array}{l}\text { Robustness } \\
\text { regarding } \\
\text { misunderstandings }\end{array}$ & 22 & 21 & 32 \\
\hline $\begin{array}{l}\text { Willingness to use } \\
\text { system } \\
\text { again }\end{array}$ & 35 & 12 & 27 \\
\hline Total average & $\mathbf{3 4}$ & $\mathbf{2 8}$ & $\mathbf{3 6}$ \\
\hline
\end{tabular}

Dari hasil pengujian tersebut dapat disimpulkan bahwa penggunaan common-sense database pada program Bot Chat tidak mutlak lebih baik dari program Bot Chat lainnya, tetapi dalam hal kemauan user untuk menggunakan kembali Bot Chat tersebut, proyek yang dikembangkan oleh Amilon memiliki nilai yang paling baik diantara seluruh program Bot Chat yang diujikan.

\section{KESIMPULAN}

Dari hasil observasi terhadap berbagai teknik desain Bot Chat yang ada, dapat disimpulkan bahwa Bot Chat sudah mulai diimplementasikan ke dalam berbagai bidang seperti kesehatan, dan pendidikan. Fitur-fitur yang ditambahkan pada program Bot Chat juga mengalami perkembangkan, mulai dari penggunaan simbol tombol keyboard hingga speech recognition. Penggunaan fitur speech recognition dapat memfasilitasi user yang memiliki keterbatasan fisik.

Berdasarkan hasil pengujian pada beberapa program Bot Chat, mayoritas dapat berkomunikasi seperti manusia. Sebuah penelitian memberikan tingkat akurasi 75\%, sementara sebagian yang lain mendekati performa salah satu Bot Chat yang terbaik yang pernah ada dengan menggunakan teknik desain yang berbeda.

\section{DAFTAR PUSTAKA}

Abbasi, Suni, Kazi, Hameedullah, 2014, Measuring Effectiveness of Learning Bot Chat Systems on Student's Learning Outcome and Memory Retention. Asian Journal of Applied Science and Engineering. Vol. 3 No. 2.

Russell, Stuart J.; Norvig, Peter (2003), Artificial Intelligence: A Modern Approach (2nd ed.), Upper Saddle River, New Jersey: Prentice Hall.

Mauldin, Michael (1994), "ChatterBots, TinyMuds, and the Turing Test: Entering the Loebner Prize Competition", Proceedings of the Eleventh National Conference on Artificial Intelligence, AAAI Press

A.S. Lokman, J.M.Zain, "Anarchitectural design of Virtual Dietitian (ViDi) for diabetic patients." pp. 408411, 2009.

A. S. Lokman, and J. M. Zain, "One-Match and All-Match Categories for Keywords Matching in Bot Chat," American Journal of Applied Sciences, vol. 7, no. 10, pp. 1406, 2010

V. Bhargava, and N. Maheshwari, "An Intelligent Speech Recognition System for Education System," 2009.

H. Al-Zubaide and A. A. Issa, "OntBot: Ontology based Bot Chat," International Symposium on Innovations in Information and Communications Technology, Amman, 2011, pp. 7-12. 